\title{
Myocardial infarction in a neonate
}

\author{
Colin L. Berry ${ }^{1}$ \\ From the Department of Morbid Anatomy, The Hospital for Sick Children, Great Ormond \\ Street, London W.C. I
}

Extensive myocardial infarction developed in a neonate, apparently as a result of paradoxical embolism from the ductus venosus. It is suggested that in instances of myocardial infarction in the very young this vessel should be examined as a possible source of the embolus.

Ischaemic injury to the myocardium is sometimes found in infants and children, both in normal hearts (Berry, 1967) and in those with hypertrophy (Tawes et al., 1969). Frank myocardial infarction with confluent necrosis of large areas of muscle is, however, extremely rare. If the origin and distribution of the coronary vessels is normal, and these vessels are not diseased, the infrequency with which infarction occurs may be inferred from the finding of reports of only 7 such cases. The purpose of this communication is to report another instance, apparently due to coronary artery embolism.

\section{Clinical history}

A male infant was delivered face to pubis at 38 weeks' gestation (birthweight 2692 g.). Soon after birth he was noted to be cyanosed and dyspnoeic. Chest $x$-ray showed slight cardiac enlargement. The infant's colour did not improve, dyspnoea increased, and further cardiac enlargement was shown radiographically. The electrocardiogram at this time was interpreted as showing non-specific changes of the ST segments and $T$ waves (Fig. $\mathbf{I}$ ). The infant was digitalized.

At 8 days of age he was transferred to The Hospital for Sick Children, Great Ormond Street. He was noted to be extremely dyspnoeic with a respiratory rate of 65 a minute, and his skin had a mottled, cyanosed appearance. The pulse rate was 125 a minute, all pulses were equally palpable, and the systolic blood pressure was $80 \mathrm{~mm} . \mathrm{Hg}$. The heart was clinically enlarged, the heart sounds were normal, and no murmurs were present. The liver was palpable four fingerbreadths below the costal margin. Chest $x$-ray showed that the heart's shadow had grossly enlarged, filling almost the entire chest. The electrocardiogram (Fig. 2) showed low voltage activity and non-specific ST-T changes. The initial electrocardiogram (Fig. I) was not available for study at this time.

1 Gillson Scholar of the Worshipful Society of Apothecaries of London.
The diagnosis was considered to be congenital heart disease, probably associated with a pericardial effusion.

At cardiac catheterization the catheter tip did not reach the lateral border of the right atrium, confirming the presence of a pericardial effusion. All right heart pressures were raised; pulmonary artery 'wedge' $32 \mathrm{~mm}$. Hg; pulmonary artery mean, $60 \mathrm{~mm}$. $\mathrm{Hg}$; right ventricle, $90 / 24 \mathrm{~mm}$. $\mathrm{Hg}$; right atrium mean, $24 \mathrm{~mm}$. Hg. All pressures showed paradoxical respiratory effect. The arterial oxygen saturation was 8I per cent, but no intracardiac shunts were present.

An attempted pericardial aspiration was unsuccessful, the infant had recurrent cardiac arrests, became progressively acidotic, and died 4 hours after the investigation.

Later inspection of the initial electrocardiogram showed Q waves in leads II, III, and aVF, raised ST segments and inverted $T$ waves in those leads, $Q$ waves in $V_{2}$ and $V_{3}$, and $T$ wave flattening in the left limb and chest leads. These changes indicated inferior wall myocardial infarction with probable septal and apical involvement.

Necropsy Permission for limited examination was obtained; the skull was not opened. Necropsy was performed 72 hours after death, the infant weighed $2.75 \mathrm{~kg}$., and was $51 \mathrm{~cm}$. in length. Significant abnormalities were confined to the cardiovascular system, and other findings will not be discussed.

The heart, which weighed 32 g., lay in a morphologically normal pericardium containing $12 \mathrm{ml}$. reddish fluid containing a firm fibrin clot. External inspection revealed a pale area toward the apex of the left ventricle, measuring $2 \times 1 \cdot 5$ $\mathrm{cm}$., with its largest axis extending up towards the atrioventricular junction along the line of the interventricular branch of the left coronary artery; $0.4 \mathrm{~cm}$. from the origin of this vessel from the left coronary artery, a $0.3 \mathrm{~cm}$. long dark-red mass could be seen - apparently in the vessel.

The cut surface (Fig. 3) showed a distinct zone of myocardial necrosis, with deeply con- 


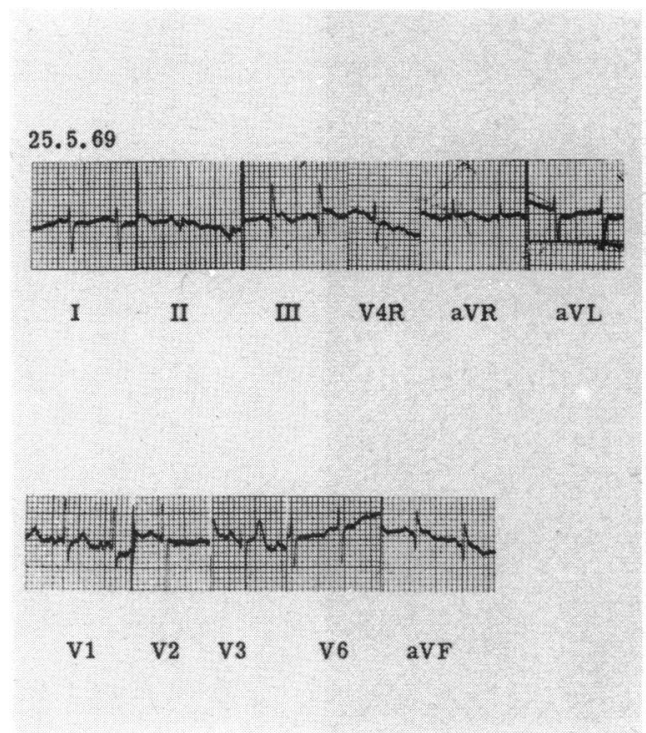

FIG. I Electrocardiogram, 25 May 1969.

gested centre and a paler peripheral area extending from the apex to within $0.2 \mathrm{~cm}$. of the atrioventricular junction. The overlying endocardium was covered by adherent thrombus.

The origin of both coronary arteries, their ostia, and the distribution of their major branches were normal. There was no morphological abnormality of the heart, the foramen ovale was probe patent, and the ductus arteriosus narrowed with a little adherent clot seen on the wrinkled endothelial aspect when the vessel was opened. The aortic arch was left sided, and distributed normal branches. The ductus venosus contained partially organized adherent laminated thrombus (Fig. 4); at its proximal end, this projected into the inferior vena cava.

Histopathology There was widespread necrosis of the myocardium with dystrophic calcification at the periphery of the necrotic area and mononuclear cell infiltration. The central area of some papillary muscles showed evidence of calcification without frank necrosis (Fig. 5). The area of the left interventricular branch of the left coronary artery, containing a reddish mass in life, was found to be occluded by a laminated thrombus containing numerous leucocytes resembling clot found in the ductus venosus (Fig. 6). This embolus shows signs of organization.

\section{Discussion}

In the absence of idiopathic arterial calcification (Brown and Richter, I94I), arterial disease, or an abnormality of origin of the coronary arteries, myocardial infarction is rare in the neonate. Of the 7 previously reported cases, 6 have been fatal, the one ex-

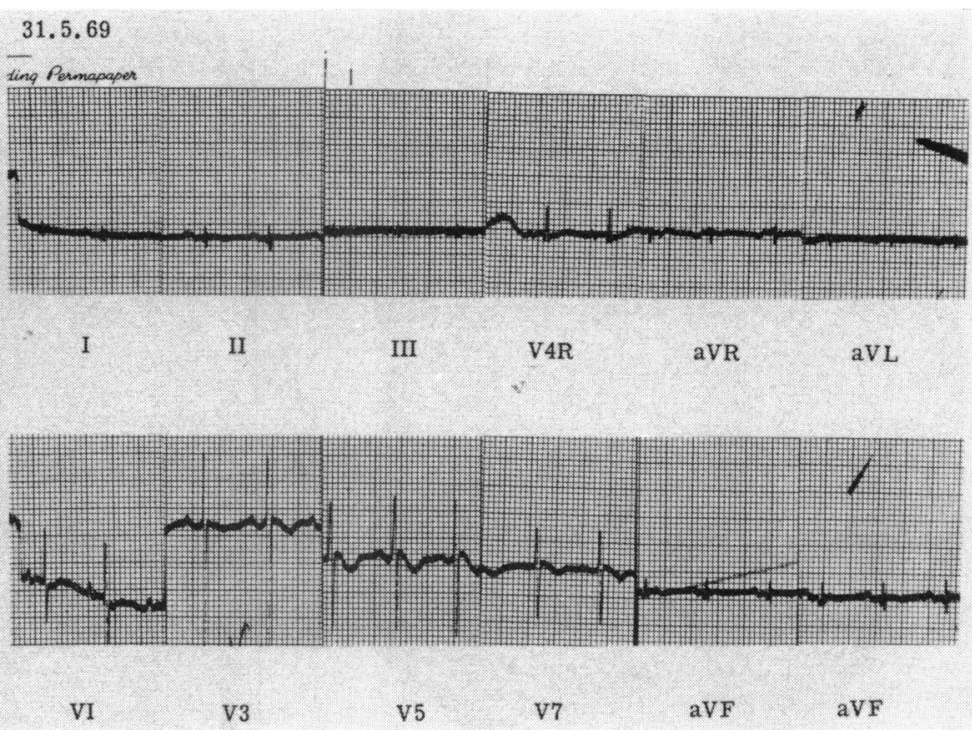

FIG. 2 Electrocardiogram, 3I May 1969.

ception being the case of Fagan et al. (1966). The pathogenesis of infarction is uncertain in a number of cases. In 3 instances, embolism to the coronary arteries was thought to be the cause of the injury (Stryker, 1946; Hauwaert, Loos, and Verhaeghe, 1967;

FIG. 3 Heart - infarcted area clearly visible, involving the apex and septum, extending upwards towards the aortic valve. $(\times 4$. FIG. 4 Liver - thrombus in the ductus venosus. $(\times 7$.

FIG. 3

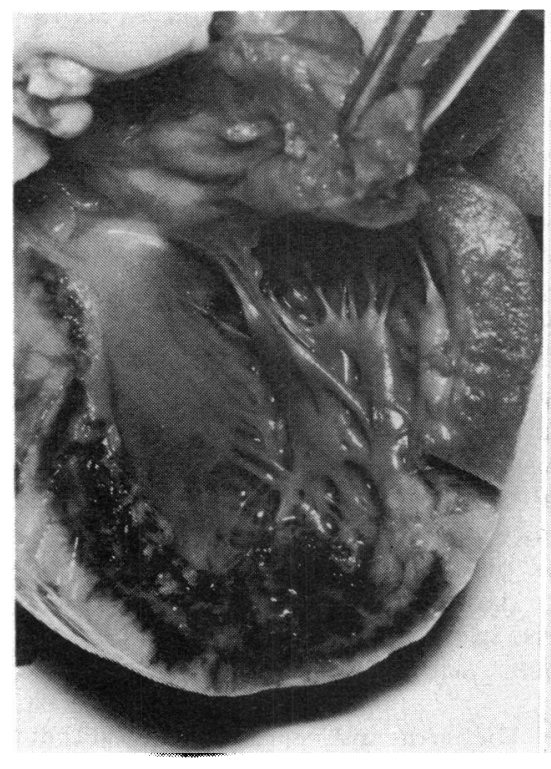

FIG. 4

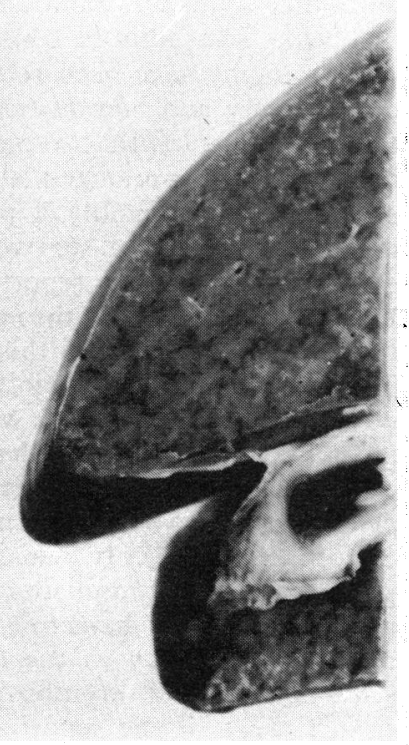


FIG. 5 Central calcification in papillary muscle. $(H$. and $E . \times 150$.

Arthur et al., 1968). Of the 2 cases reported by Ravich and Rosenblatt (1947), one showed evidence of arterial disease and is not discussed further here. In their second case, an infant with normal vessels, a cardiac venous thrombosis was found at necropsy and other smaller intramuscular vessels were involved. The authors considered that this change might have been related to the difficult delivery and administration of pituitary to the mother, with coronary artery spasm in the infant. A prolonged labour with breech extraction was possibly a predisposing factor in the long-term survivor (Fagan et al., 1966), and in the case reported by Gault and Usher (1960) in which thrombosis of adrenal veins was also found. In this latter case focal intimal thickening and endothelial irregularity of the left coronary artery was also seen, but in our experience this change is not uncommonly seen in the neonatal heart without evidence of myocardial injury (see also Schornagel, 1956). It remains possible that prolonged labour and tissue damage may allow a potentially dangerous rise in thromboplastin-like activity in the foetus with subsequent danger of thrombosis.

In Case $I$ of the report by Richardt and

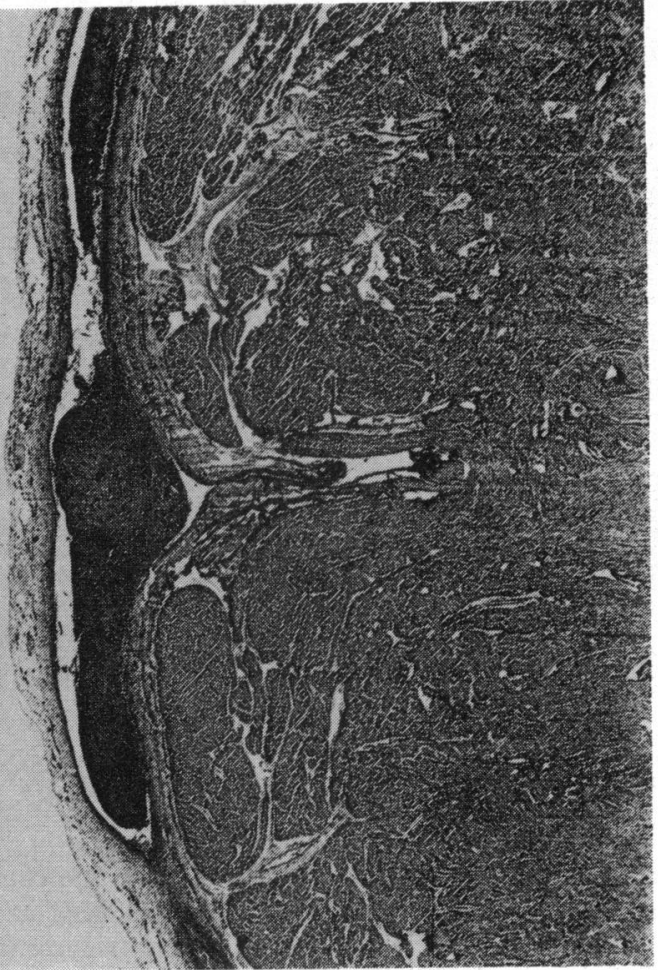

FIG. 6 Embolus in branch of left coronary artery. $(H$. and $E . \times 30$.)

Benirschke (1959) there was no evidence of arterial disease or embolism. Infarction in this infant was limited in involving the mitral papillary muscle, and might be explained by a 'poor perfusion' type of ischaemic injury (see Berry (1967) and Fig. 5). Though frank infarction in these circumstances is uncommon, it may be seen in the central core of the papillary muscles in hypertrophied hearts after perfusion during open heart surgery.

In our case, paradoxical embolism from the ductus venosus probably occurred via the patent foramen ovale, as in the infant described by Arthur et al. (1968). The ductus arteriosus was also patent, but not widely so, and though it might offer an alternative origin for the embolus, this seems unlikely. The 'long' survival of this case ( 9 days from probable infarction) allowed the beginning of organization of the embolus and some dystrophic calcification to occur, though this latter change may occur very rapidly (within 48 hours) in the injured neonatal myocardium.

It seems likely that embolic injury is the commonest cause of myocardial infarction in the neonate with normal vessels, and the findings in this case, and that of Arthur et al. (1968), suggest that the ductus venosus should 
be inspected in any infant dying from myocardial infarction.

The author thanks Dr. Eric D. Silove for his help in the preparation of the clinical summary; and Dr. M. J. Simpkiss of the Royal Victoria Hospital, Bournemouth, for permission to publish the details of the case.

\section{References}

Arthur, A., Cottom, D., Evans, R., and Spencer, H. (1968). Myocardial infarction in a newborn infant. Fournal of Pediatrics, 73, 110.

Berry, C. L. (1967). Myocardial ischaemia in infancy and childhood. Fournal of Clinical Pathology, 20, 38.

Brown, C. E., and Richter, I. M. (I94I). Medial coronary sclerosis in infancy. Archives of Patho$\log y, 31,449$.

Fagan, L. F., Thurmann, M., LoPiccolo, V. F., and Byrne, P. A. (1966). Myocardial infarction in the perinatal period with long-term survival. fournal of Pediatrics, 69, 378.
Gault, M. H., and Usher, R. (1960). Coronary thrombosis with myocardial infarction in a newborn infant. New England fournal of Medicine, 263, 379.

Hauwaert, L. G. van der, Loos, M. C., and Verhaeghe, L. K. (1967). Myocardial infarction during exchange transfusion in a newborn infant. fournal of Pediatrics, 70, 745.

Ravich, R. M., and Rosenblatt, P. (1947). Myocardial infarction in the newborn infant. Fournal of Pediatrics, 31, 266.

Richardt, R., and Benirschke, K. (1959). Myocardial infarction in the perinatal period: report of two cases in newborn infants. Fournal of Pediatrics, 55, 706.

Schornagel, H. E. (1956). Intimal thickening in the coronary arteries in infants. Archives of Pathology, 62, 427.

Stryker, W. A. (1946). Coronary occlusive disease in infants and in children. American fournal of Diseases of Children, 71, 280.

Tawes, R. L., Jr., Berry, C. L., Aberdeen, E., and Graham, G. (1969). Myocardial ischaemia in infants: its role in three common congenital cardiac anomalies. Annals of Thoracic Surgery, 8, 383. 